RESEARCH ARTICLE

\title{
Effect of Age and Life Characteristics on Variations of the Heart Rate Variability Parameters among Active Manual Workers
}

Authors

J. Varga ${ }^{1}$, K. Kardos ${ }^{1}$, I. Nagy ${ }^{1}$, F. Kudász ${ }^{1}$, L. Szirtes ${ }^{2}$

Affiliations

${ }^{1}$ National Public Health Centre. Budapest, Hungary

${ }^{2}$ Metal-Carbon Ltd. Budapest, Hungary

\section{Correspondence}

L. Szirtes

Email: szirtes.laszlo@metalcarbon.hu

\section{Abstract}

Objectives: Due to innovation developments new methods can be applied also in the field of occupational health. Results of physiological measurements carried out in the workplace during work support the observation that age and life characteristics of the examined persons, work environment, working system, the working process significantly influence the changes of heart rate variability (HRV) parameters. These sources of information may be useful in developing health-oriented prevention programs.

Methods: The physiological measurements were performed in the workplace in lying (resting) position, during the working process their results (HR, TP, VLF, LH, HF) were processed by correlation and regression analysis and statistically evaluated as a function of age and life characteristics (hypertension, smoking, body mass) and metabolism-syndrome parameters.

Results: Evaluation of the results of nearly 4000 physiological measurements carried out in the workplace of more than 1000 participants showed that age had a close positive correlation with heart rate and close negative correlation with the HRV parameters (TP, VLF, LF, and HF). Considering also life characteristics (hypertension, smoking, body mass index, cholesterol, and triglyceride) beside age, can provide useful information which can be beneficial to develop healthoriented prevention programs.

Conclusions: The results call attention to the possibilities of applying new methods (like HRV analysis) in the field of occupational health and work safety which can be used in the future in education, research, or organization of work, and for interest the health and safety of workers. The developments are multidisciplinary, complex and require the collaboration of physicians, engineers, computer scientists, and mathematicians.

Key words: physiological measurements, HRV parameters, age and life characteristics, prevention programs, innovation in occupational health. 


\section{Introduction}

Due to innovation developments, new methods can be applied also in the field of occupational health. This includes the possibility of using the method of heart rate variability (HRV) analysis. /27/, /29/. The application of heart rate variability analysis in the case of cardiac insufficiency and myocardial infarction has been well-known in the clinic for several decades. However, according to the literature $/ 1,2,3,4 /$, only few report have been published internationally in the field of occupational health for various reasons.

Variations of HRV parameters are influenced by several factors like age, years of service, life characteristics (hypertension, smoking, body weight), heart rate, and blood pressure, but they are also influenced by work performance, shift work, length of working time, leisure time activity, rest time, travel and accommodation conditions, as well as individual characteristics /28/. The European Society of Cardiology and the North American Society of Pacing and Electrophysiology published a Directive in $1996 / 5 /$ on the uniform interpretation of heart rate variations, determination of measurement methods, and definition of physiological relationships.

In the present paper, we are focusing on examining the effects of age, years of service, life characteristics, and the combination of all these. /30/. Our goal is to understand the logic and extent of variations of the HRV parameters, the unfavorable range of each parameter, and through the knowledge of the parameters to explore the possibilities of health protection and influencing it. We aim to gain a more accurate knowledge of the factors influencing the condition of the human body through the innovation of tools and methods and to contribute to the modernization of health protection regulations by outlining the limits of biomarkers.

Out of the 5,000 workplace measurements carried out with the participation of more than 1,200 people in the Hungarian extractive industry, our publication details the results of 2401 measurements of 720 people (all men) at 7 plants. /23/, /24/, /25/.

Similar to the decrease in HRV parameters detected in heart failure and cardiovascular lesions, our measurements show a significant decrease in HRV, especially in the case of the elderly and those with life characteristics like $\mathrm{H}$ (hypertension), $\mathrm{S}$ (smoking), and $\mathrm{Ti}$ (body mass index) $>1.24$, as well as in work with unfavorable work schedules. Based on the logic of the change in parameters, we may have a good reason for the possibility of using HRV analysis methods in the field of occupational health. Determination of combined limit values that can be formed based on biological markers cannot be, in principle, excluded, but it is a researchintensive task.

\section{List of the abbreviations:}

$\mathrm{H}$ : hypertension

nH: no hypertension

RRs: systolic blood pressure (mmHg)

RRd: diastolic blood pressure

S: smoking

nS: non-smoking

Ti: Body Mass Index = body weight

$(\mathrm{kg}) / 0.79$ x body height $(\mathrm{cm})-$

60.7

TP: total power $(0-0.40 \mathrm{~Hz})$

VLF: very low frequency $(<0.04$

$\mathrm{Hz}$ ) 
LF: low frequency $(0.04-0.15 \mathrm{~Hz})$

$\mathrm{HF}$ : high frequency $(0.15-0.4 \mathrm{~Hz})$

$\mathrm{LF} / \mathrm{HF}$ ratio: $\mathrm{LF}$ (ms2) / HF (ms2)

HR: heart rate (pulse)

Ym: years in mine (work years)

SD1, RMSSD: time domain coefficients

TRIG: triglyceride

\section{Methods}

\subsection{Study population}

Employees of seven raw material extraction and processing plants took part in our research between 2005 and 2017 aimed at learning about the work strain of the human organism. The workplace investigations reported in the present paper included the activities of a total of 720 people in 2401 shifts. The participants were all men qualified fit for work by the required aptitude tests. The workplace physiological measurements were performed by the National Public Health Centre (NPHC). Before the measurements, the workers agreed in writing to participate in the instrumental measurements after being informed of the purpose of the tests. The study was conducted following the Helsinki Declaration as modified in 1983 and 1989, with the permission of the Scientific and Research Ethics Committee of the Medical Research Council (Budapest). We complied with the regulations on personal data protection when processing the data.

\subsection{Execution of the workplace measurements}

The measurements were performed at the plants with the POLAR S 810 heart rate monitor, which is suitable for measuring and storing HRV. The tests were started by measuring blood pressure (OMRON M3) and continued by an interview regarding personal data (age, years of service, body height, body weight, smoking habit, health complaints). This was followed by mounting the sensor of the monitor on the chest and starting the instrument. The 10-minute, resting measurements were performed in lying position using camp beds in the occupational physicians' offices or in other noise-free separated rooms supplied with clean air. The POLAR instrument was worn by the workers full-time, shut down, and dismantled at the end of the shift, and the recorded data were stored on a laptop. Working processes during shifts were monitored and recorded in the traditional way by recording points of time. 612 people working in the same workplace took part in the measurements at the same time. Measurements were taken at all three parts of the day (morning, afternoon, night) and every working day of the shift (1-7 working days). A significant number of workers involved in workplace measurements were also involved in ergometric (Jaeger Oxycon Champion walking band) tests at $\mathrm{NIOH}$.

The POLAR recording - during the initial lying rest period and then during the entire shift - is illustrated in Figure 1. 


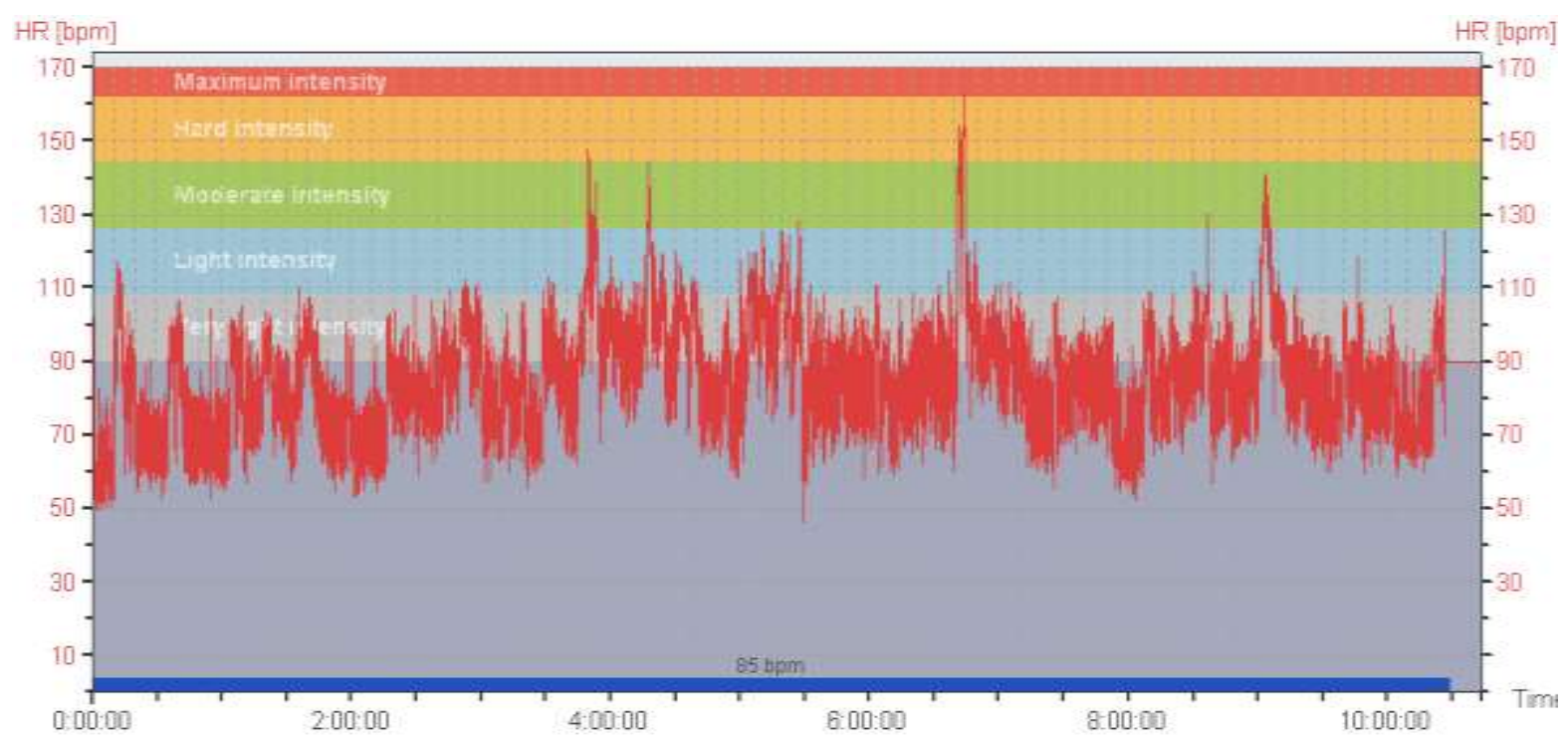

Figure 1. POLAR recording (lying resting and full time)

\subsection{Statistical treatment of the measurement data}

The data stored on the computer were arranged in Excel spreadsheets according to the directives of the European Society of Cardiology and the North American Society for Pacing and Electrophysiology HRV Standards of Measurement, Physiological Interpretation, and Clinical Use $/ 5 /, / 29 /$ as time domain (error rates) and frequency domain (TP ranges: VLF, LF, HF and LF/HF) data.

The statistical analysis included descriptive details (mean, 95\% confidence intervals, variance, standard deviation, $\max / \mathrm{min}$, skewness) and the dependence of the parameters on life characteristics $(\mathrm{H}, \mathrm{S}, \mathrm{Ti})$ (standard SPSS Version 13.0 and then SPSS 23; SPSS Inc., Chicago, and IBM). The comparison also included analysis of individuals, groups, shifts, and part of the day, and working processes. SPSS is one of the most common tools in multivariate studies, we used SPSS Linear Models and Linear Regression Procedures. Linear models make it possible to examine the relationships between a continuous dependent variable and one or more so-called predictor variables. Although we used more than 25 variables to describe the phenomena, due to the closeness of the correlation relationships, fewer (5-10) variables were included in the modeling of the individual phenomena.

It is worth mentioning that the functioning of the human body is eurhythmic and the relationship of physiological variables is stochastic /4/, but the linear analysis of the relationships with close regression relations and two or more factors correctly reflects the nature of the changes and there is no significant difference in the extent, either.

The dependence of each HRV parameter on age and years of service was analyzed by Linear Models, mostly by Automatic Linear Models of SPSS. This program performs automatic data preparation, analysis of residuals, determines outliers, and computes model coefficients. We also examined the correlation relationships between each influencing factor and the HRV parameters. 
We tested the normality of the variables and the results of each regression relationship were checked by sensitivity analysis. Our paper is based on the use of the lying-rest data values.

\section{Results}

It is known from the literature that HR, RR, RRs/RRd and HRV parameters are influenced by age, lifestyle (H, S, Ti), /6/, /7/, /29/ work, work environment, work organization (shift work and length of daily working time) $/ 7 /$ and in addition to other circumstances, even some individual conditions. Our paper presents the effects of age, years of service, and life characteristics $(\mathrm{H}, \mathrm{S}, \mathrm{Ti})$ and their combinations observed in our investigations.

\subsection{Correlation relationships}

There was a close correlation (> 0.5 , sig.:0.000) between HR and time domain, as well as frequency-domain evaluated error rates and HRV parameters. With this in mind, we examined the relationships between age and years of service, and life characteristics. It was found that there was usually a close (> 0.5 , sig. $=0.000)$ correlation between timeand frequency-domain-based parameters. (The correlation between RRs and $\mathrm{Ti}$ and HRV is only of "medium" closeness.)

Table 1. Correlation relationships (where closeness of the relationships among the parameters is

$>0.3$, and sig. $=0.00$ )

\begin{tabular}{|c|c|c|c|c|c|}
\hline Age (years) & HF: -0.737 & LH/HF: +0.732 & LF: -0.688 & TP: -0.662 & RMSSD:- 0.465 \\
\hline RRs & TP: -0.542 & LF: -0.518 & HF: -0.461 & & \\
\hline BMI & RRs: +0.362 & HF: -0.305 & LF: -0.303 & & \\
\hline HR & RMSSD: -0.640 & SD1: -0.627 & LF: -0.419 & HF: -0.419 & \\
\hline TP & HF: +0.967 & VLF: +0.987 & LF: +0.960 & RMSSD:+ 0.688 & SD $1:+0.678$ \\
\hline LF/HF & Age: +0.732 & TP: -0.579 & RMSSD $:-0.525$ & & \\
\hline
\end{tabular}

It can be seen from Table 1 that in lying rest position, the correlation relationship was closest between age and HRV parameters, and HF and LF parameters occurred most frequently.

\subsection{Effect of age on the changes of $H R V$ parameters}

Evaluation of the relationships between age and HRV parameters /8/, /9/ was based on the measurements performed at the start of work in lying rest position. Considering the methodological materials of the literature $/ 9 /$, $/ 10 /, / 11 /, / 12 /$, we determined the linear regression relationships between age and HRV parameters by Linear Models of the SPSS program. As examples, the agedependent changes in HR and TP, and also in $\mathrm{HF}$ and RRs are shown in Figures 2 and 3, respectively. 


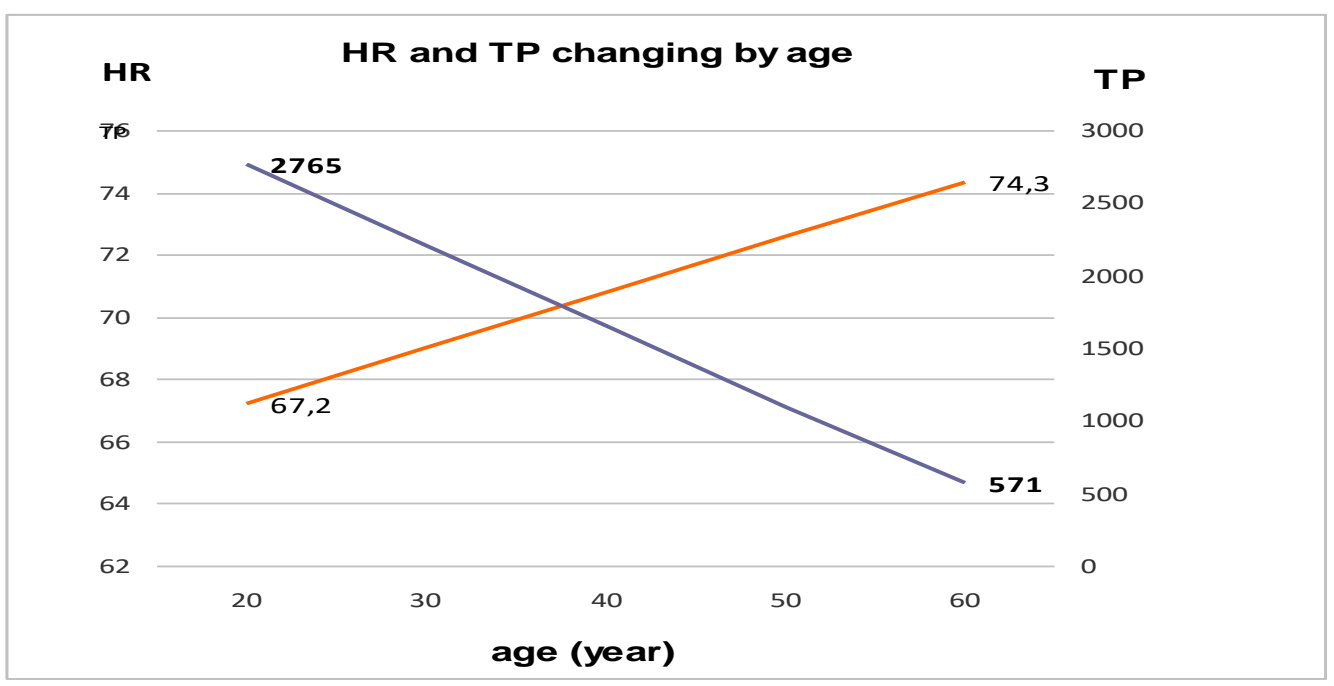

Figure 2. Age-dependent changes of HR and TP

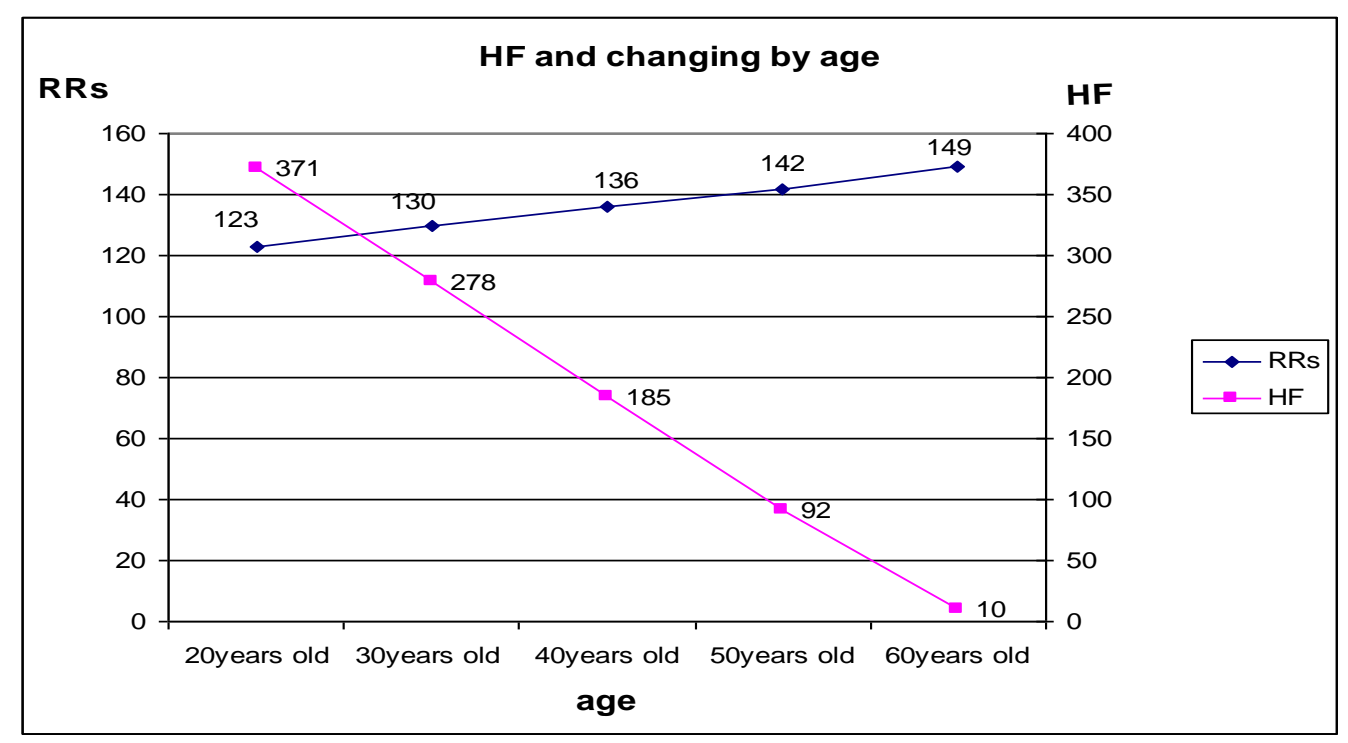

Figure 3. Age-dependent changes of HF and RRs

Figures 2 and 3 show that the heart rate (HR) and blood pressure (RRs $\mathrm{mmHg}$ ) values in the younger age group were significantly better than those in the older age group. At the same time, the HRV parameters (TP and HF) were significantly reduced. 


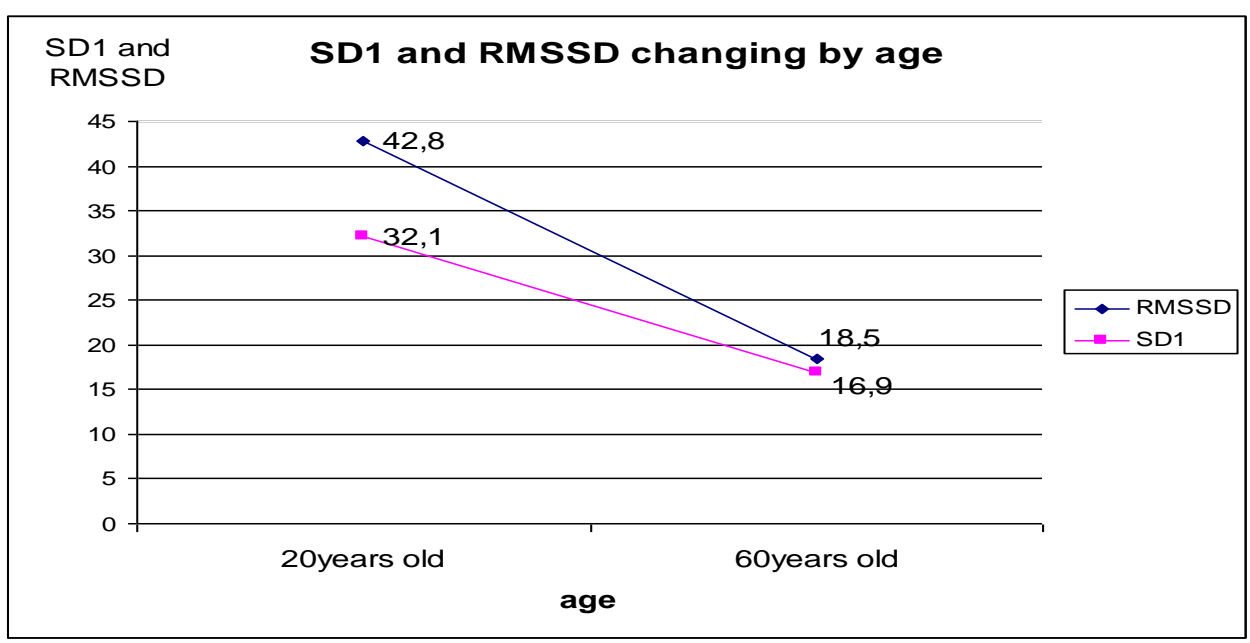

Figure 4. SD1 and RMSSD in relation to age

Figure 4 illustrates that the change in the parameters of the HRV time domain (SD1, RMSSD) and frequency domain (TP / Figure $2 /$, and HF / Figure $3 /$ ) is of the same nature as a function of age. The age-dependent changes $/ 11 /, / 12 /$ of all examined parameters are shown in Table 2. The information of these relations can be used in the field of occupational health, limit values can be formed, and in case they are reached, it is expedient to take measures to prevent health damage.

Based on the results of the statistical analysis we performed comparative studies, using average values of the data shown in Tables 2 and 3 and taking into account individual life characteristics (age, length of service, body weight, smoking habit, blood pressure, heart rate) and average values of the HRV parameters. Compared to the average values of the whole data set, the influential effect of smoking, hypertension and body weight on variations of the HRV parameters could be perceived.

We found that the measured values (TP, LF. $\mathrm{HF}$ ) of smokers (43\%) decreased by $10 \%$ compared to the HRV parameters of the total 2401 samples, while the time domain (SD1 and RMSSD) values decreased by almost $15 \%$. The effect of smoking on HRV parameters - in the case of the studied subjects - is illustrated in Figure 5.

$37 \%$ of the subjects had hypertension, the effect of hypertension on HRV parameters (TP and HF) exceeded the reduction caused by smoking, as shown in Figure 6. Agedependent changes /11/, /12/ of all examined parameters are shown in Table 2.

According to Table 2, the HRV parameters, both the time domain and the frequency domain ones, decreased with age, except the heart rate (HR / min), and the LF / HF ratio. /13/, /14/, /15/.

From the 2401 samples examined, three groups were formed to illustrate the effects of life characteristics on HRV parameters. In addition to the mean values regarding the whole data set, Table 3 shows the values of individuals with "favorable" status $(<33$ years, $\mathrm{nS}, \mathrm{nH}, \mathrm{BMI}<0.9)$ and those with increased hypertension (RRs $>160 \mathrm{mmHg}$ ). The difference between the values of the HRV parameters (TP, LF, HF) of the groups is twice in the case of favorable/average, and the difference exceeds four times in the case of favorable/increased $\mathrm{H}$. 
J. Varga, et al. Medical Research Archives vol 9 issue 10. October $2021 \quad$ Page 8 of 16

Table 2. Effects of smoking (S) and hypertension $(\mathrm{H})$ on the HRV parameters

\begin{tabular}{|c|c|c|c|c|c|c|c|c|c|c|c|c|}
\hline Designation & $\begin{array}{c}\text { Sample } \\
\text { size (n) }\end{array}$ & $\begin{array}{c}\text { Age } \\
\text { (years) }\end{array}$ & $\begin{array}{c}\text { Years of } \\
\text { employment }\end{array}$ & Ti & RRs & HR & SD1 & RMSSD & TP & LF & HF & LF/HF \\
\hline $\begin{array}{c}\text { Whole data } \\
\text { set }\end{array}$ & 2401 & 42.6 & 16.3 & 1.11 & 138 & 71.3 & 16.9 & 23.2 & 1324 & 379 & 158 & 2.67 \\
\hline S (43\%) & 1036 & 43.1 & 17.2 & 1.09 & 138 & 74.7 & 14.4 & 19.9 & 1195 & 341 & 140 & 2.74 \\
\hline $\mathrm{nS}(57 \%)$ & 1365 & 42.6 & 15.7 & 1.13 & 137 & 68.6 & 18.8 & 25.7 & 1421 & 409 & 172 & 2.61 \\
\hline $\mathrm{nH}(63 \%)$ & 1510 & 40.6 & 14.4 & 1.07 & 128 & 68.6 & 19.7 & 27.1 & 1649 & 476 & 204 & 2.5 \\
\hline $\begin{array}{c}\text { H1 (26\%) } \\
\text { n }\end{array}$ & 624 & 45.7 & 19.4 & 1.17 & 147 & 74.7 & 12.8 & 17.8 & 819 & 230 & 87 & 2.87 \\
\hline $\begin{array}{c}\text { Increased H } \\
(11 \%) .\end{array}$ & 267 & 48.5 & 20.0 & 1.21 & 168 & 78.4 & 10.4 & 14.6 & 663 & 184 & 64 & 3.08 \\
\hline
\end{tabular}

Table 3. HRV parameters of favorable, average and increased hypertension groups

\begin{tabular}{|l|l|l|l|l|l|l|l|}
\hline Group & $\begin{array}{l}\text { Sample } \\
\text { size (n) }\end{array}$ & Age (years) & Ti & HR/min & TP m/s2 & LF m/s2 & HF m/s2 \\
\hline Favorable & 66 & 26.7 & 0.88 & 65 & 2647 & 819 & 410 \\
\hline Average & 2401 & 42.8 & 1.11 & 71.2 & 1324 & 379 & 158 \\
\hline $\begin{array}{l}\text { Increased } \\
\text { H }\end{array}$ & 267 & 48.5 & 1.21 & 78.4 & 663 & 184 & 64 \\
\hline
\end{tabular}

Favorable group: $<33$ years, $\mathrm{nS}, \mathrm{nH}, \mathrm{Ti}=0.88$

Average group: 42.8 years, $\mathrm{H}(37 \%), \mathrm{S}(43 \%), \mathrm{BMI}=1.11$

Increased H group: RRs > 160/mmHg 

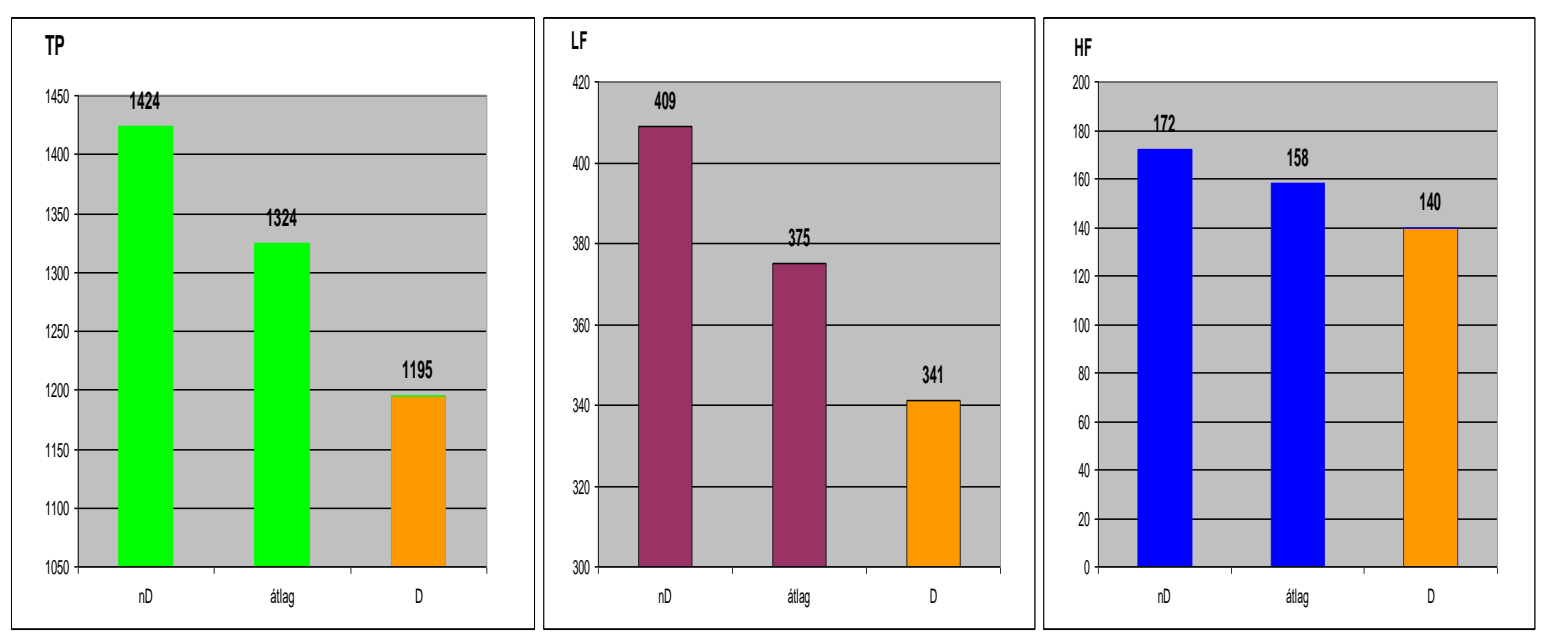

Figure 5. Effects of smoking (S) on the HRV parameters (2401 samples, S: 43\%, nS: 57\%) $\mathrm{TP}, \mathrm{LF}, \mathrm{HF} \mathrm{m} / \mathrm{s}^{2}$
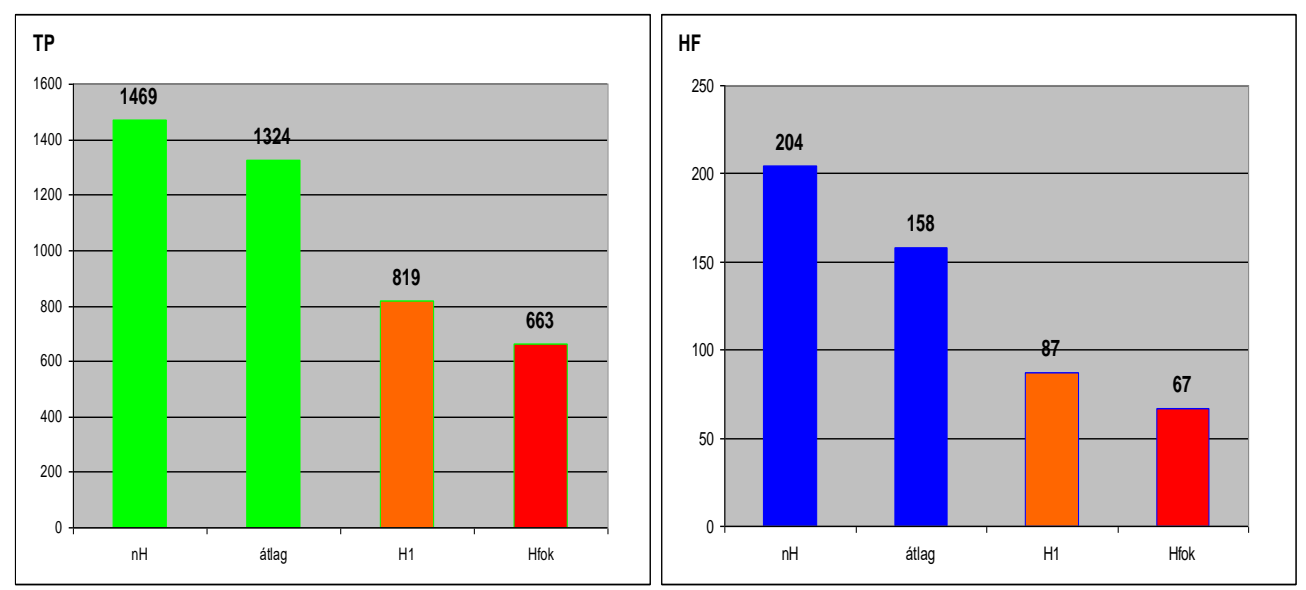

Figure 6. Effects of blood pressure (RRs) on the HRV parameters (TP, HF, m/s $\mathrm{s}^{2}$ )

nH (RRs < $139 \mathrm{mmHg})$, sample size: 1510

H1 (RRs = 140-159 mmHg, sample size: 624

Increased H (RRs > $160 \mathrm{mmHg}$ ), sample size: 267 


\section{Changes in the HR and HRV spectrum ranges by age}

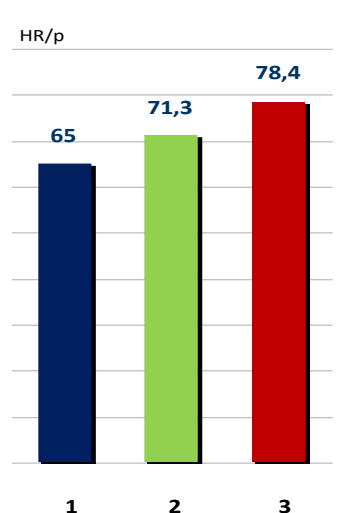

1. :Favourable (66 samples):

2. :Average (2401 samples):

3. :Unfavourable (267 samples):

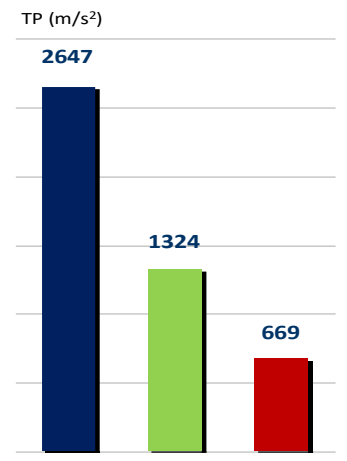

1

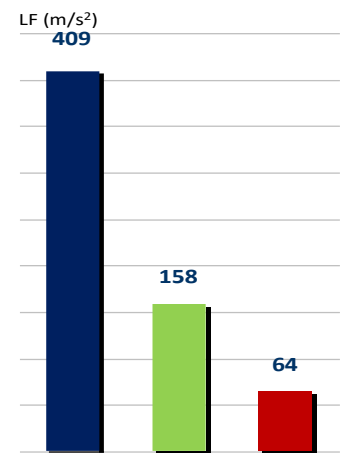

1

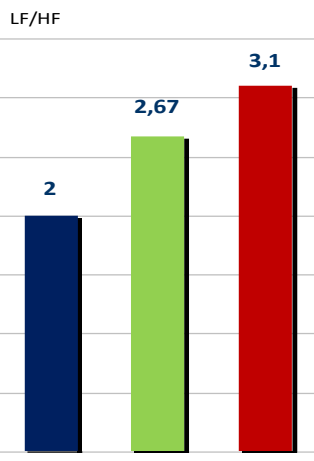

1

age $<33$ years old, $\mathrm{nH}, \mathrm{nS}, \mathrm{Ti}<1$ age 42,8 years old, $H$ (37\%), $S(43 \%), T_{i}=1,11$ age 48,5 years old, Hypertonia $R R>160 T_{i}=1,21$

Figure 7. Changes in the HR and HRV spectrum ranges by age and life characteristics

Figure 7 illustrates that in the three groups formed, the HR (heart rate) increases from the favorable group to the unfavorable, the range of TP and LF decreases, and the value of LF / $\mathrm{HF}$ also increases. The direction and extent of the change in the parameters draw attention to the possibilities of utilizing the results (the red color means unfavorable).

The results of our studies are in harmony with the extensive literature results regarding the application of the HRV method, according to which age and living conditions - ultimately a person's state of health - can be monitored through changes of cognizable parameters.
129/. Table 3 and the information on the significantly different data in the three groups draw attention to the applicability of the method.

Using the "Automatic Linear Modelling" method, we examined the effects of factors influencing HRV parameters. In Fig. 8 the value of HF is shaped by 5 factors with close correlation relationships (age, hypertension, smoking, years spent in mine, and BMI). Among the factors, age represents $72.4 \%$. The reliability of the test is confirmed by the low value of the information criterion and the sig. $=0.000$. 


\section{Predictor Importance}

Target: HF

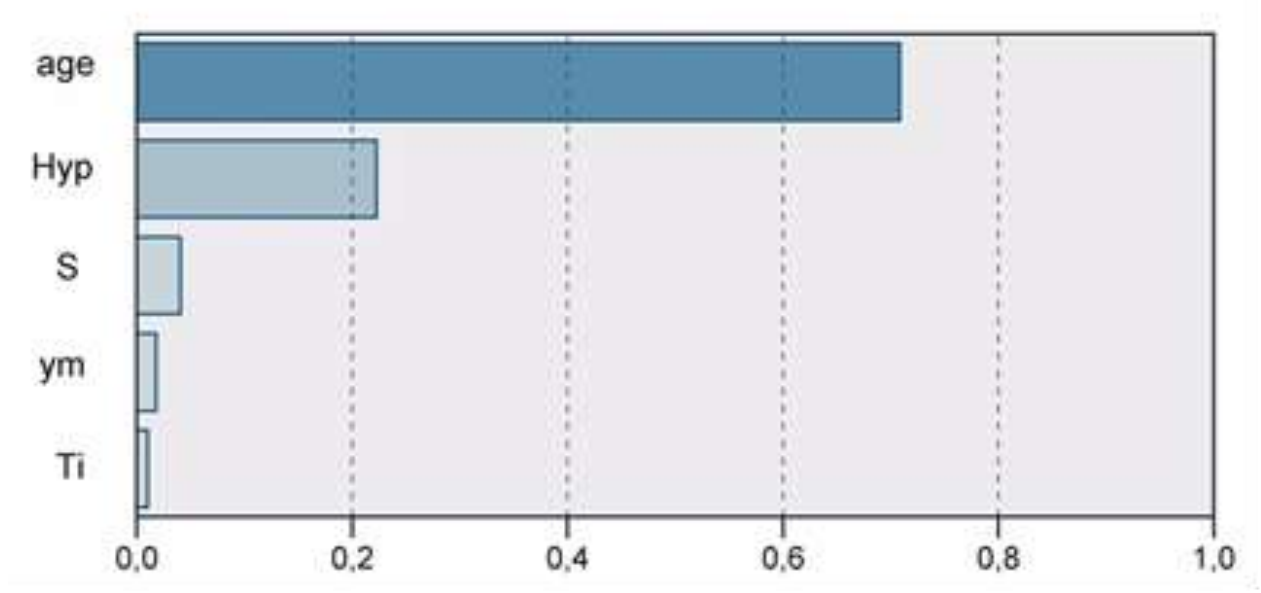

Figure 8. Importance of predictors (Target: HF)

Based on the correlation relationships, age has the greatest effect on changes in HRV parameters. Figure 8 shows the factors influencing the HF parameter. /16/. The numerical relationships, as a result of linear regression analysis, are presented in Table 4.

Table 4. Dependence of parameters on age 2341 samples, mean age: 42.8 years; $\mathrm{H}=34 \%$; $\mathrm{S}=43 \%$; $\mathrm{Ti}=1.11$

\begin{tabular}{|c|c|c|c|c|c|}
\hline Parameters & $\begin{array}{c}20 \\
\text { years }\end{array}$ & $\begin{array}{c}30 \\
\text { years }\end{array}$ & $\begin{array}{c}40 \\
\text { years }\end{array}$ & $\begin{array}{c}\mathbf{5 0} \\
\text { years }\end{array}$ & $\begin{array}{c}\mathbf{6 0} \\
\text { years }\end{array}$ \\
\hline $\mathrm{HR}=0.161 \times($ years $)+64.486$ & 67.7 & 69.3 & 70.9 & 72.5 & 74.1 \\
\hline RRs $=0.576 \times$ (years) +112.428 & 124 & 130 & 135 & 141 & 147 \\
\hline$R R d=0.250 \times($ years $)+70.560$ & 76 & 78 & 81 & 83 & 86 \\
\hline $\mathrm{SD} 1=-0.580 \mathrm{x}($ years $)+42.318$ & 30.7 & 24.9 & 19.1 & 13.3 & 7.5 \\
\hline RMSSD $=-0.807 \times($ years $)+58.914$ & 42.8 & 34.7 & 26.6 & 18.6 & 10.5 \\
\hline $\mathrm{TP}=-52.748 \times($ years $)+3662.711$ & 2608 & 2080 & 1553 & 1025 & 498 \\
\hline VLF $=-25.668 \times($ years $)+1928.84$ & 1415 & 1159 & 902 & 645 & 389 \\
\hline VLF\% $=0.39 \times($ years $)+43.889$ & 51.7 & 55.6 & 59.5 & 63.4 & 67.3 \\
\hline$L F=-17.107 \times($ years $)+1136.98$ & 795 & 624 & 453 & 282 & 111 \\
\hline LF\% $=-0.143 \times($ years $)+34.385$ & 31.5 & 30.1 & 28.7 & 27.2 & 25.8 \\
\hline $\mathrm{HF}=-9.77 \times($ years $)+586.685$ & 391 & 294 & 196 & 98 & 34 \\
\hline $\mathrm{HF} \%=-0.246 \times($ years $)+21.674$ & 16.8 & 14.3 & 11.8 & 9.3 & 6.8 \\
\hline LF/HF $=0.049 \times($ years $)+0.611$ & 1.59 & 2.08 & 2.57 & 3.06 & 3.55 \\
\hline
\end{tabular}


Table 4/1. Extent of changes in the parameters

\begin{tabular}{|l|c|c|c|c|}
\hline \multicolumn{1}{|c|}{ Parameter changes } & $20-29$ years & $\begin{array}{c}30-39 \\
\text { years }\end{array}$ & $\begin{array}{c}40-49 \\
\text { years }\end{array}$ & $\begin{array}{c}50-59 \\
\text { years }\end{array}$ \\
\hline HR increase during 10 years: unit & 1.6 & 1.6 & 1.6 & 1.6 \\
\hline RRs increase during 10 years: unit & 6 & 5 & 6 & 6 \\
\hline RRd increase during 10 years: unit & 2 & 3 & 2 & 3 \\
\hline TP decrease during 10 years: \% & 20 & 25 & 34 & 51 \\
\hline LF\% decrease during 10 years: \% & 1.4 & 1.4 & 1.5 & 1.4 \\
\hline HF\% decrease during 10 years: \% & 2.5 & 2.5 & 2.5 & 2.5 \\
\hline LF/HF increase during 10 years: unit & 0.49 & 0.49 & 0.49 & 0.49 \\
\hline
\end{tabular}

According to Table 4, the HRV parameters - both the time domain and the frequency domain ones decrease with increasing age /17/, /18/ - except for HR/min (heart rate), and the LF/HF ratio).

\section{Discussion}

The results are based on the evaluation of 2401 measurements performed in 7 plants with the participation of 720 people following the plant work schedule. The examined individuals worked in shift work schedules (2-7 days shifts). /29/.

The resting measurements in lying position were performed for 10 minutes before the start of work in separate rooms under undisturbed conditions. The measured HRV parameters were evaluated by age, shift work time (years of service), and life characteristics (such as hypertension, smoking, body weight, and combinations of all these) using the SPSS program.

We determined the correlations between the changes of each measured physiological parameter, which were usually close $(>0.5$ and sig.:0.000) to each other. It has been found that there is usually a close relationship between the parameters determined by time domain and frequency domain evaluation methods. This phenomenon allows us to perform combined analyses that we also used.
The effects of age change on each HRV parameter can be seen in Figures 2, 3, and 4, and the numerical results determined from the regression relationships in Table 4 show the direction and extent of the changes.

Table 4/1 shows the changes in each HRV parameter by 10 years, from which a dynamic (from $20 \%$ to $51 \%$ ) decrease in the TP range can be observed. This phenomenon is consistent with that one seen in heart failure, which draws attention to the adverse physiological effects of shift work schedule.

The effects of years of service on HRV parameters can be examined by regression methods in a way analogous to age dependence. The symptoms of longer-term changes (decreased HRV parameters) call attention to the possibilities and importance of the prevention of changes.

Of the three groups formed, the most unfavorable physiological effect was found in the case of patients with hypertension that manifested in an increase in heart rate and a decrease in TP ranges. At the same time, the 
LF / HF ratio increased in this group (3.08) and at the age $>50$ years.

$43 \%$ of the participants were smokers. The adverse effects of smoking on HRV parameters (Figure 5) succeeded age and hypertension, respectively - presumably, the extent of smoking may change the order. /19/

The unfavorable effect of the increase of body mass index (average value: 1.11) on the change of HRV parameters can be ranked $6^{\text {th }}$ out of the seven factors considered, but depending on the degree of obesity, it can differ significantly and justify an individual examination.

Based on the data of the three groups formed on the basis of life characteristics (Table 3), we can state that in the case of the 267 individuals belonging to the unfavorable group (increased hypertension: RRs > 160 $\mathrm{mmHg}$, age $=48.5$ years, $\mathrm{Ti}=1.21$ ), all measured values differed significantly from the data of the group (66 individuals) with favorable classification characteristics (age < 39, $\mathrm{nH}, \mathrm{nS}, \mathrm{Ti}<1)$.

According to Table 2, the group mean value of blood pressure increased from 138/81 to $168 / 89$, and the $\mathrm{HR} / \mathrm{min}$ value increased from $65 / \mathrm{min}$ to $78 / \mathrm{min}$. However, the timedomain error rates were reduced by $34 \%$ $55 \%$ for each interval evaluated.

The TP range decreased to $25 \%$ (one-fourth) (663/2647). It is worth noting that in the case of the HF band the decrease changed to $15.6 \%$ (64/410), which means a significant increase of the parasympathetic effects. As a result, the LF / HF ratio increased to 1.15fold.

The results of our workplace measurements by accordance with the literature /20/, /21/ show the applicability of the HRV method in the field of occupational health. The results of
HRV measurements make it possible to develop a substantial health protection program. $/ 21 /$.

\section{Limitations}

Pre-study surveys did not include a more detailed exploration of smoking habits (e.g., how long they have been smoking and how much they smoked daily). The knowledge of this information could have enriched the results of the evaluation. Neither drinking habits nor leisure activities were included in the data collection, either, because - based on our initial experience - the reliability/reality content of this information was uncontrollable and would have caused confusion in the evaluation of the results.

\section{Conclusions}

The present paper by the title is limited only to the determination and assessment of parameters collected at rest in lying position out of the full-time period measurements taken at the workplace. The findings revealed that the HRV analysis method can provide essential information to substantiate the changes in occupational health and safety activities and regulations by understanding the influences of age and life characteristics./20/, /21/, /28/.

The results of the measurements made in the supine resting state based on the variation of HRV parameters, age, years of service, and life characteristics, as well as their assessment by groupings, support the possibility of understanding the logic of HRV parameter variation. This requires a large number of measurements to be carried out at the unit under study, taking into account the multitude of influencing factors.

By using the HRV method, in addition to examining the effect of age and life characteristics, it is possible to learn about the effects of working conditions (e.g. shift work 
and length of working time, nature of work) and to implement a more physiologically favorable working variant in practice.

The results of workplace physiological measurements carried out with the participation of individuals with unfavorable conditions may justify special examinations to be carried out in those concerned, for which the conditions should be created.

Innovation can help to refine research results by developing new measurement tools and evaluation methods. The developments are multidisciplinary, complex, and require the collaboration of doctors, engineers, computer scientists, and mathematicians. /28/, /29/, /30/

\section{Acknowledgments}

The workplace physiological measurements were carried out under the coordination of the Scientific Committee on Mining Health and Ergonomics of the Hungarian Academy of Sciences. The Committee provided a forum for ongoing technical discussions of the partial results.

Thanks are due to the managers of the enterprises and plants for providing the conditions for the measurements, to the occupational health and technical experts of the plants for their active participation in the implementation, and to the employees who participated in the workplace measurements for their interested and helpful cooperation. 


\section{References}

1. Bigger JT, JL Fleiss, RC Steinman et al. RR Variability in healthy middle-aged persons compared with patients with chronic coronary heart disease or recent acute myocardial infraction. doi.org/10.1161/01.CIR.91.7.1936

2. Malik M., Camm J. Dynamic Electrocardiography. 2004. Blackwell Futura. ISBN:0-4051-1960-8

3. Kamath VM, Watanabe AM., Upton RM. A. Heart Rate variability (HRV). CRC Press. 2013. ISBN: 978-1-4398-4980-4

4. Gernot E. Heart Rate variability. 2014. Springer. DOI:10.1007/978-1-44714309-3

5. Task Force of the European Society of Cardiology and the North American Society of Pacing and Electrophysiology. Heart rate variability standards of measurements, physiological interpretation and clinical use. Circulation. 1996; PMID:8737210

6. Yamasaki Y., M.Kadoma, M Matsuhisa et al. Diurnal heart rate variability in healthy subjects: effects of aging and sex difference. DOI:10.1152/ajphert.1996. 271.1. H303

7. Yeragani VK, E Sobolewski, J Kay, et al. Effects of age on long-term heart rate variability. Cardiovascular Research. Doi:10.1016/s0008-6363(97)00107-7

8. Umetani K, DH Singer, R McCraty et al. Twenty-four hour time domain Heart Rate Variability and Heart Rate: relations to age and gender over nine decades.ROI:10.1016/s07351097(97)00554-8

9. Fukusaki C., Kawakuba K., YamamotoY. Assessment of the primary effect of aging on heart rate variability in humans. DOI:10.1007/BF022780/6

10. Braun Ch, P Kowallik, A Freking et al. Demonstration of nonlinear components in heart rate variability of healthy persons.
Doi.org/10.1152/ajpheart:1998.275.5H15 77

11. Agelink MW, R Malessa, B Baumann et al. Standardized tests of heart rate variability: normal ranges obtained from 309 healthy humans and effects of age, gender and heart rate.

DOI:10.1007/BF02322093

12. Kuss O, B Schumann, A Kluttig et al. Time domain parameters can be estimated with less statistical error than frequency domain parameters in the analysis of heart rate variability. doi:10.1016/jelectrocard.2008.02.014 Epub 2008.

13. Vandeput S, B Verheyden, AE Aubert, SV Huffel. Nonlinear heart rate variability in a healthy population: influence of age. DOI: $10.1109 / C I C .2008 .4748975$

14. Acharya UR., KP Joseph, N Kannathal, Chao M, J S Suri. Heart rate variability: a review. doi:10.1007/s11517-006-0119-0

15. Acharya UR, N Kannathal, OW. Sing et al. Heart rate analysis in normal subjects of various age groups. doi:10.1186/1475925x-3-24

16. Goldberger JJ., S Challapalli, RTung, M, .A Parker, A H. Kadish. Relationship of HRV to parasympathetic effect. doi.org/10.1161/01.cir.103.15.1977

17. Corino VD, M Mattencci, LT Mainardi. Analysis of heart rate variability to predict patient age in a healthy population. DOI:10.1055/s-0038-1625405

18. Dietrich DF, Ch Schindler, J Schwartz et al. Heart rate variability in an aging population and its association with lifestyle and cardiovascular risk factors: results of the SAPALDIA study. doi.org/10.1093/europace/en1063

19. Ditrich DF, J Schwartz, Ch Schindler et al. Effects of passive smoking on heart rate and blood pressure: on 
observational study. doi:10.1093/ije/dym031

20. Amelswort L.G, EG Schouten, AC Maan et al. Occupational determinants of heart rate variability. doi:10.1007/s004200050425

21. Togo F and M Takahasi. Heart Rate Variability in Occupational Health - a Systematic Review. doi: 10.2486/indhealts 47.589

22. Oberlinner $\mathrm{C}, \quad \mathrm{M} \quad \mathrm{G}$ Ott , M Nasterlacch, M Yong. P Messer, A Zober, S Lang Medical program for shift workers - impacts on chronic disease and mortality outcomes. , doi.10.5271/sjweh.1332.

23. Varga J, J Porszasz, S Kovacs Work load and adaptation in Hungarian mines. Complex physiological measurements. Designing for Everyone Proceedings of 11-th Congress IEA Paris 1991.Taylor\&Francis, ISSN 00140139

24. Varga J, S Kovacs, J Fazekas. Classification of mine-work using the result of working place physiological measurements. XII-th Congress of IEA Toronto. 1993 ISBN:0 7484 00605

25. Varga J, J Porszasz. Investigation of the exertion requirements and the relation of age by Hungarian miners. Procedings 13th. IEA Congress. Tampere. 1997. From Experience to Innovation. ISBN:951-802-197-X

26. Varga J, J Porszasz, J Fazekas Characterization of the complex load of miners utilizing the data increment in heart rate, body temperature and other physiological variables during work. XIV Congress of IEA. San Diego. 2000. ISBN: 978-945289135

27. Varga J, Opportunities in the measurement of workload based on research results in physiology and ergonomics (in Hungarian) ISSN:1417-1015

28. Varga J, Physioergo method of workplaces survey (in Hungarian) Munkavédelem és Biztonságtechnika. ISSN 0865-3151

29. Varga J, Chapters of Physioergonomics (in Hungarian) Budapest. BányaegészségügyBányabiztonság Alapitvány. ISBN 978-963-08-1338-9. 2012

30. Varga J, I Nagy, L Szirtes, J Porszasz. Physiological strain in the Hungarian mining industry: the impact of physical and psychological factors. doi.org/10.13075/ijomeh.1896.00616 